\title{
10 días de recorrido por el majestuoso paraíso Amazónico
}

Por: Arenas, Catalina, Salazar, Dirlenis, Torrado, María Fernanda, Villalba, Lía María, Villamarín R., Erika.

Esta bio-galería muestra de una forma Iconográfica como los estudiantes de sexto semestre de Licenciatura en Biología las impresiones de la práctica de campo en uno de sus eje Curriculares (Interacción) donde a partir de esta experiencia se ponen en juego todas sus habilidades investigativos en el ámbito disciplinar y educativo para dar respuestas parciales a preguntas multidisciplinares que involucran la noción de territorio y ambiente que tienen los diferentes actores sociales de la región.

\section{Titulo:}

\section{INMENSIDAD AMAZÓNICA}

Fecha: 27 de abril de 2009

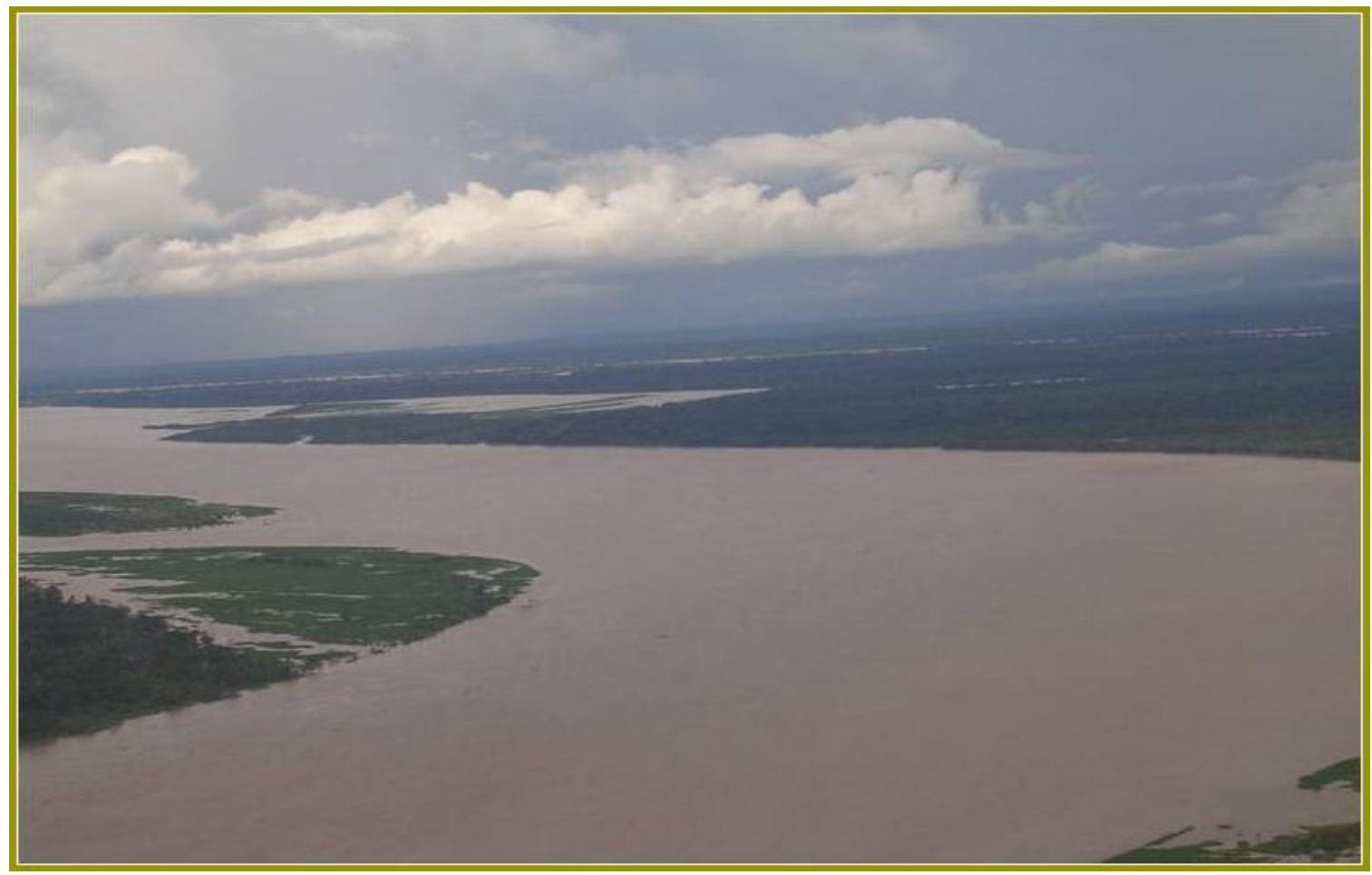

EL río Amazonas hizo su imponente aparición cuando el avión ya estaba apunto de aterrizar, su inmensidad asusta pero a la vez deleita los corazones curiosos de los observadores. 


\section{Titulo:}

\section{CULTURA INDÍGENA RESGUARDO MONILLAMENA EN LETICIA}

Fecha: 28 de abril de 2009

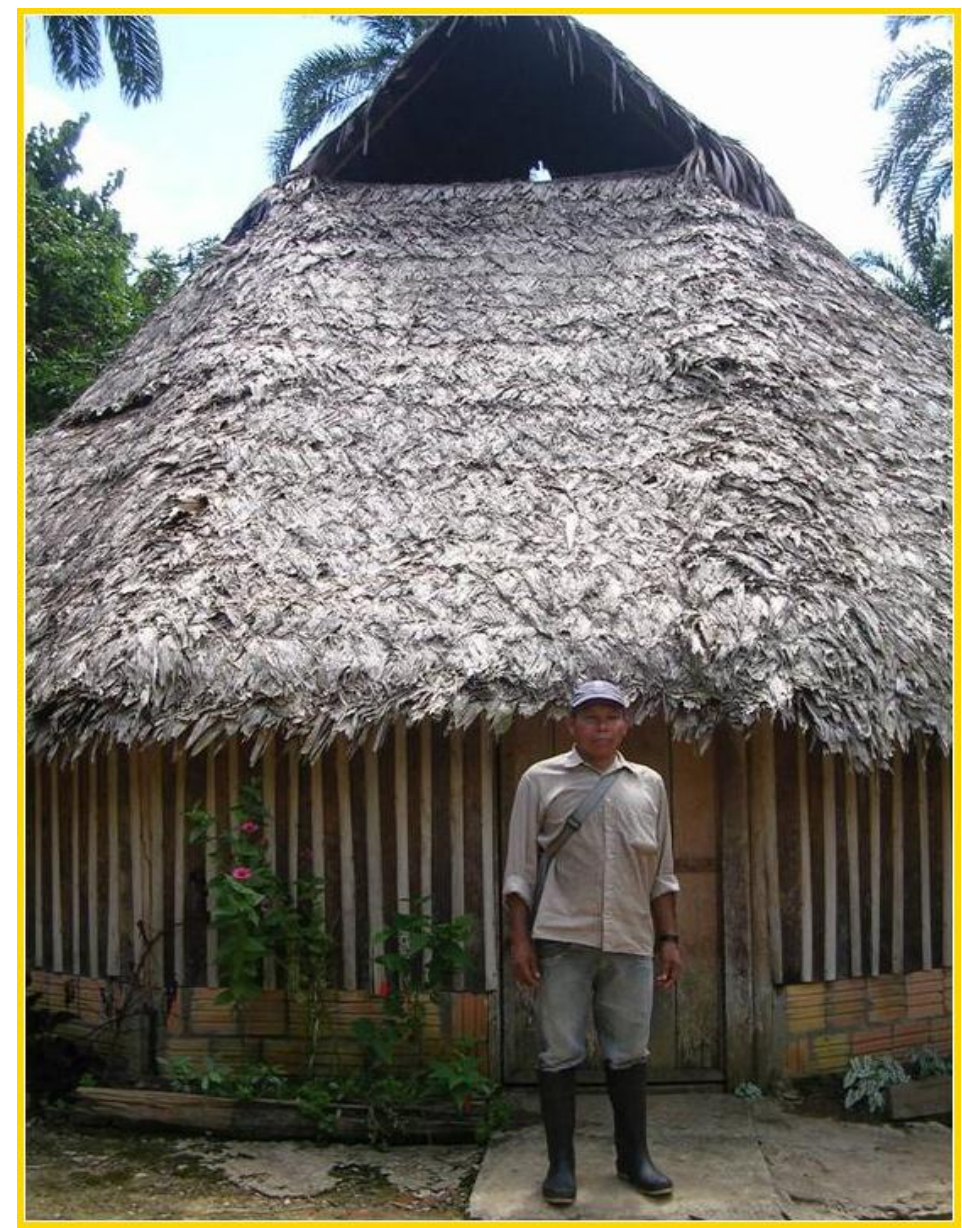

Amazonas...

La cultura indígena en muy poco tiempo ha pasado a un segundo plano en el ámbito cultural del país, pero afortunadamente aún se conservan corazones nobles, humildes y valientes que se arriesgar a perpetuarla aunque sea en su misma comunidad. 
Titulo:

\section{LA MAJESTUOSIDAD CULTURAL Y BIOLÓGICA DEL AMAZONAS}

Fecha: 29 de abril del 2009

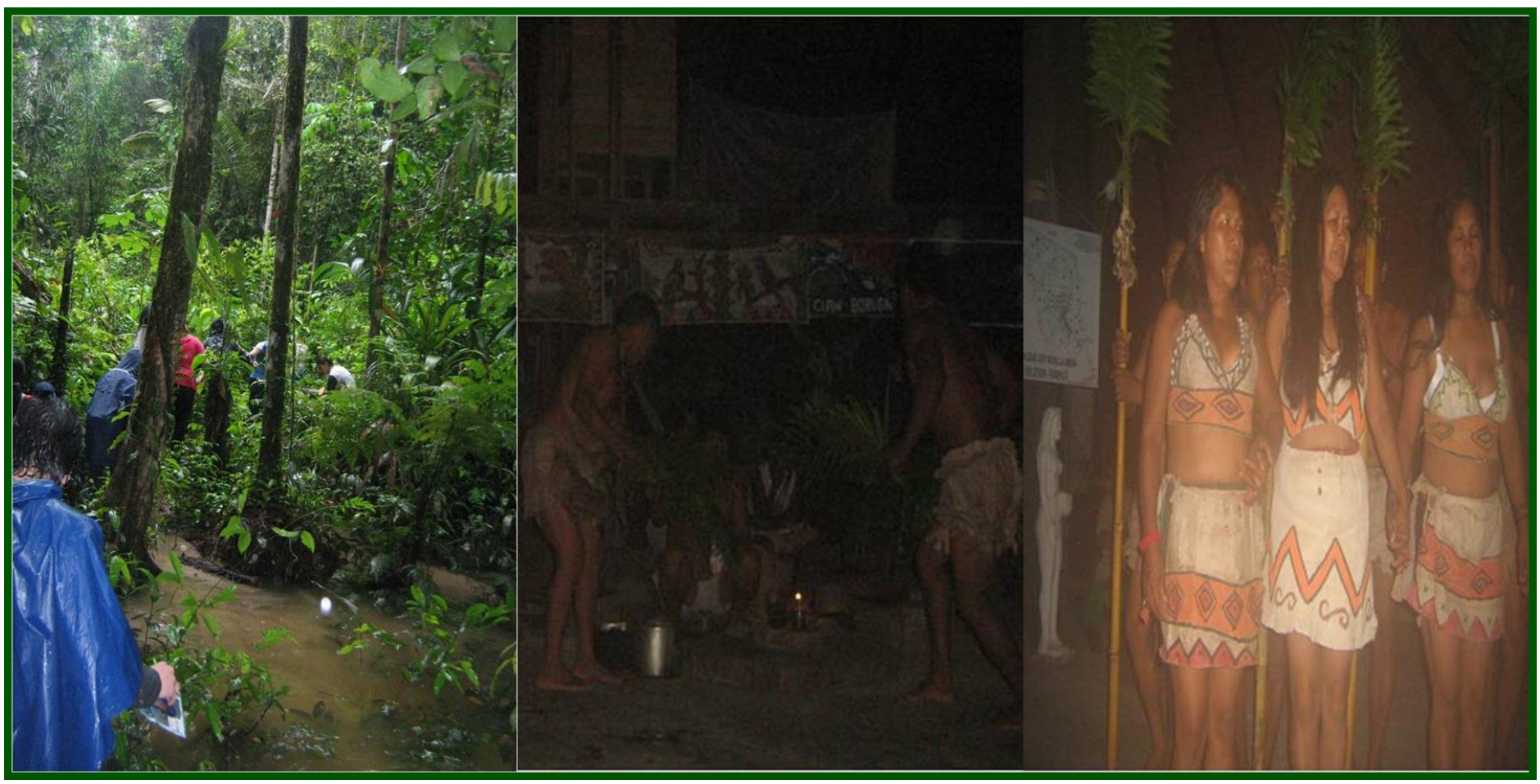

El Amazonas desde dos puntos de vista: la cultural y la biológica y cómo estos se relacionan para poder dar explicación a los hechos y fenómenos de la naturaleza, a partir del recorrido por ETI SELVA CORAZÓN en el "Sendero infierno verde" y IaS experiencias cantos y bailes en la comunidad Monillamena 


\section{Titulo:}

\section{OBSERVANDO LA GRANDEZA Y FANTASÍA DEL RIO AMAZONAS}

Fecha: 30 de abril del 2009

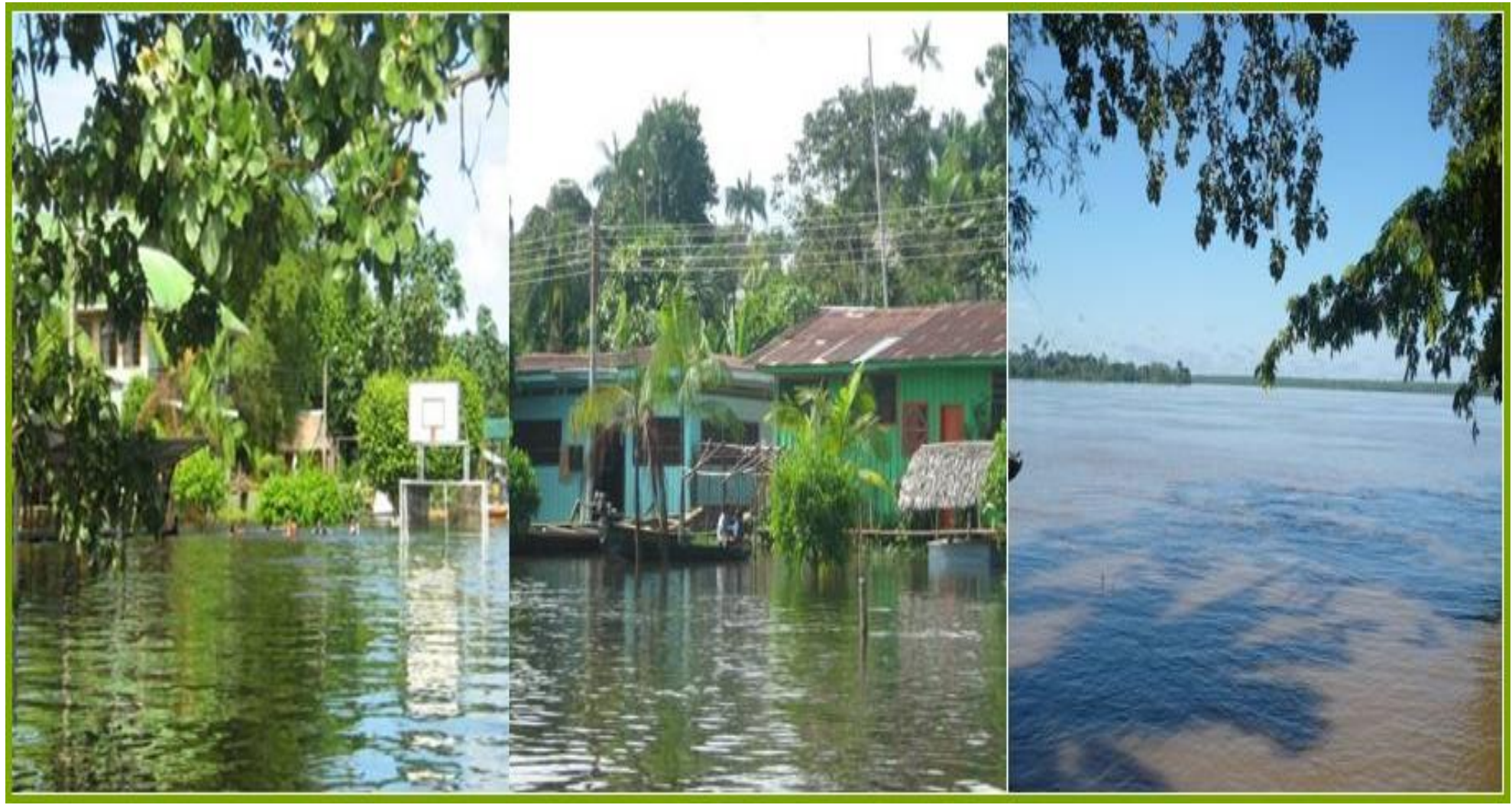

El río Amazonas y sus afluentes, en esta temporada es un río de aguas altas, el cual cubre gran parte de la zona terrestre; esto fue evidenciado cuando se realizaba el desplazamiento de Leticia a Puerto Nariño, la zona más próxima al río se encontraba inundada 


\section{Titulo:}

Delfines...

Fecha: 1 de mayo de 2009

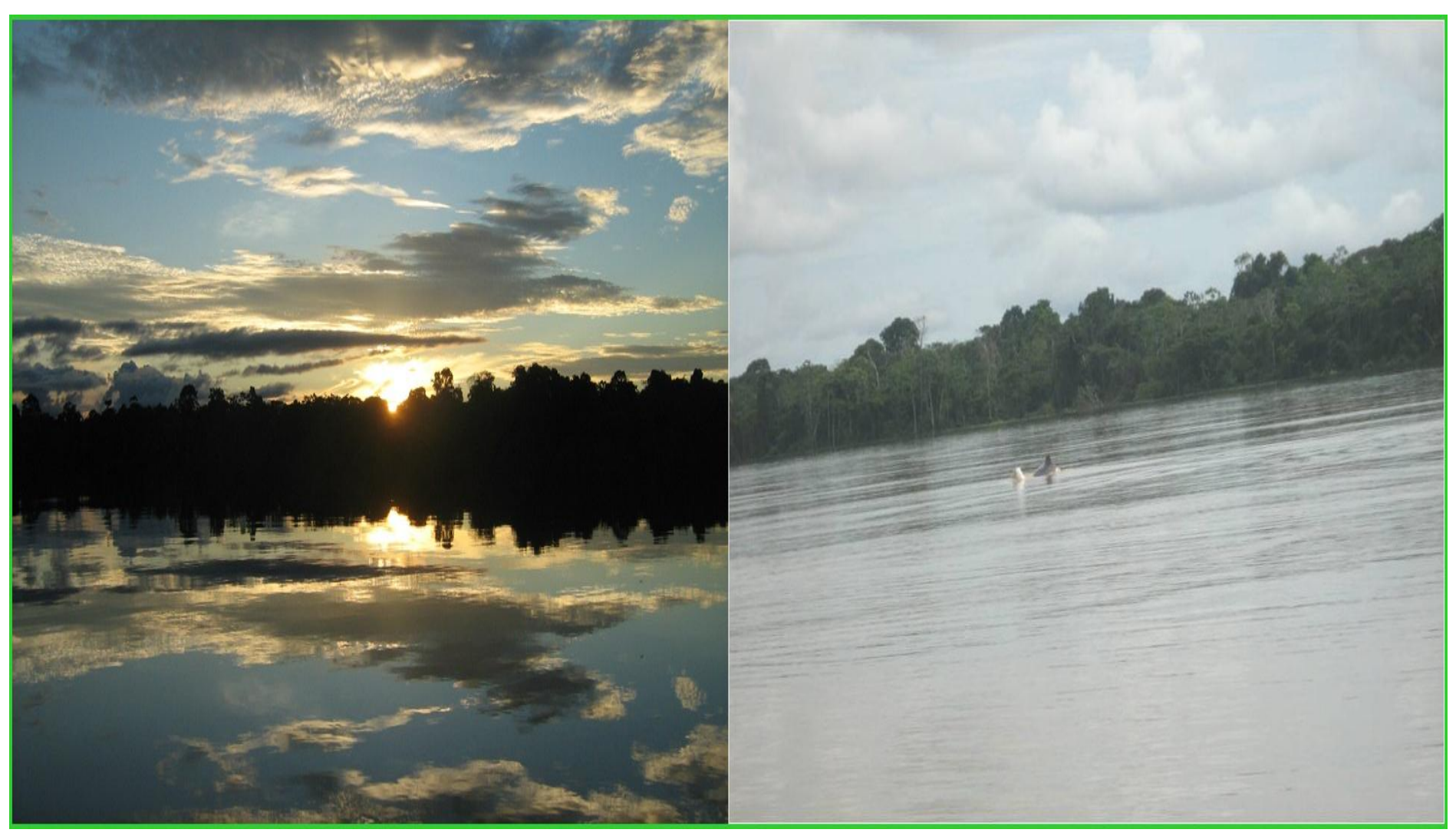

Un espectáculo natural ofrecido por el Rjo amazonas y toda su grandeza, los delfines se acercaron y se pudo observar este inolvidable avistamiento de uno de los animales más maravillosos del planeta y de todo el amazonas, acompañado del fantástico atardecer de un día en el paraíso. 


\section{Titulo:}

Bienvenidos a San Juan de Atacuari

Fecha: 2 de mayo de 2009

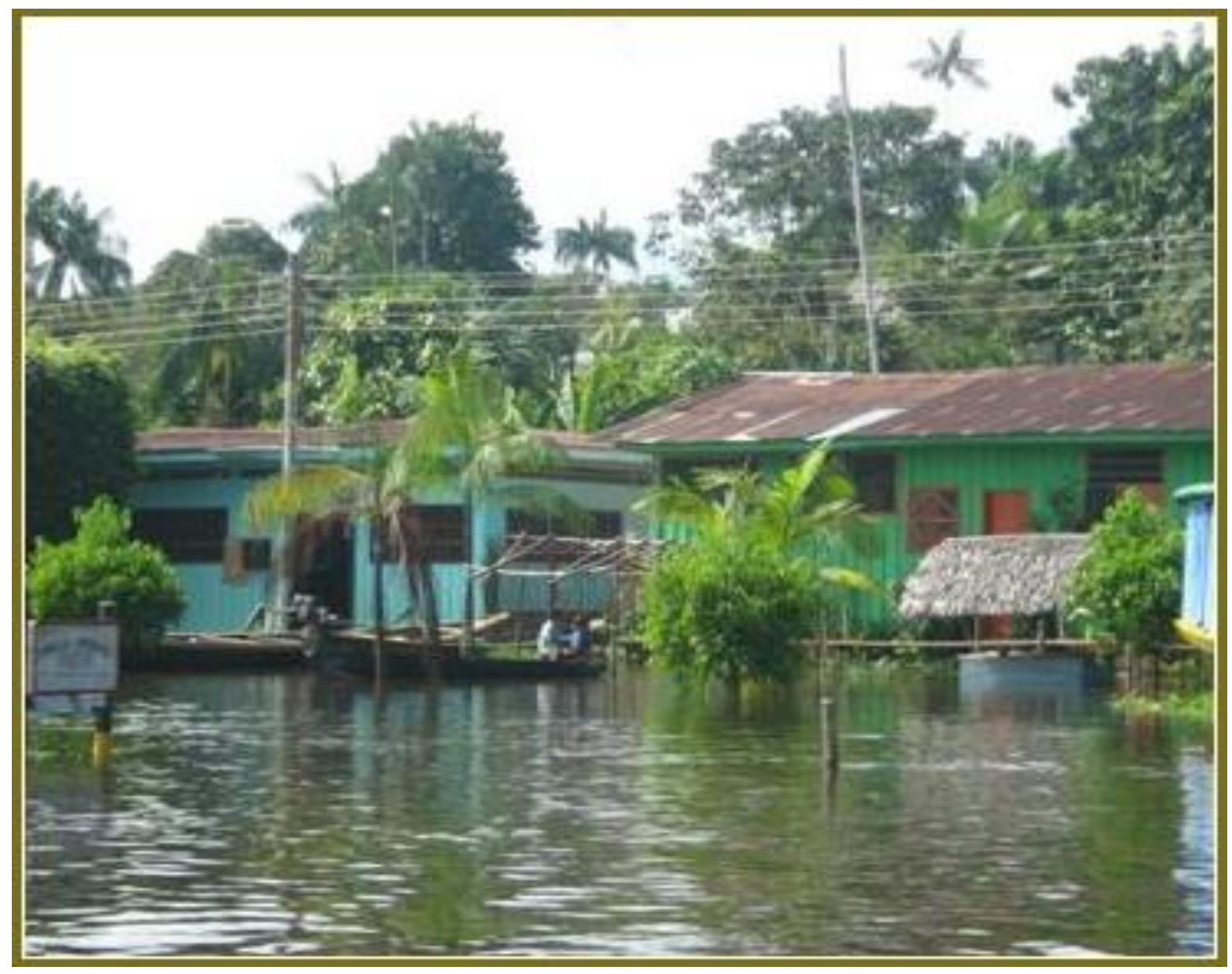

San Juan de Atacuari, el último pueblo del Amazonas ubicado al lado derecho del río Atacuari, es un lugar poco habitado y con representantes de la cultura Cocama, que invita a conocer y a disfrutar de la calidez de sus habitantes y de lo hermoso del paisaje. Al ladito del Perú.... Eso no importa aún es Colombia. 
Titulo:

CENTRO NATUTAMA: AMBIENTES ARTIFICIALES PARA LA CONSERVACIÓN DE LA VIDA.

Fecha: 3 de mayo de 2009

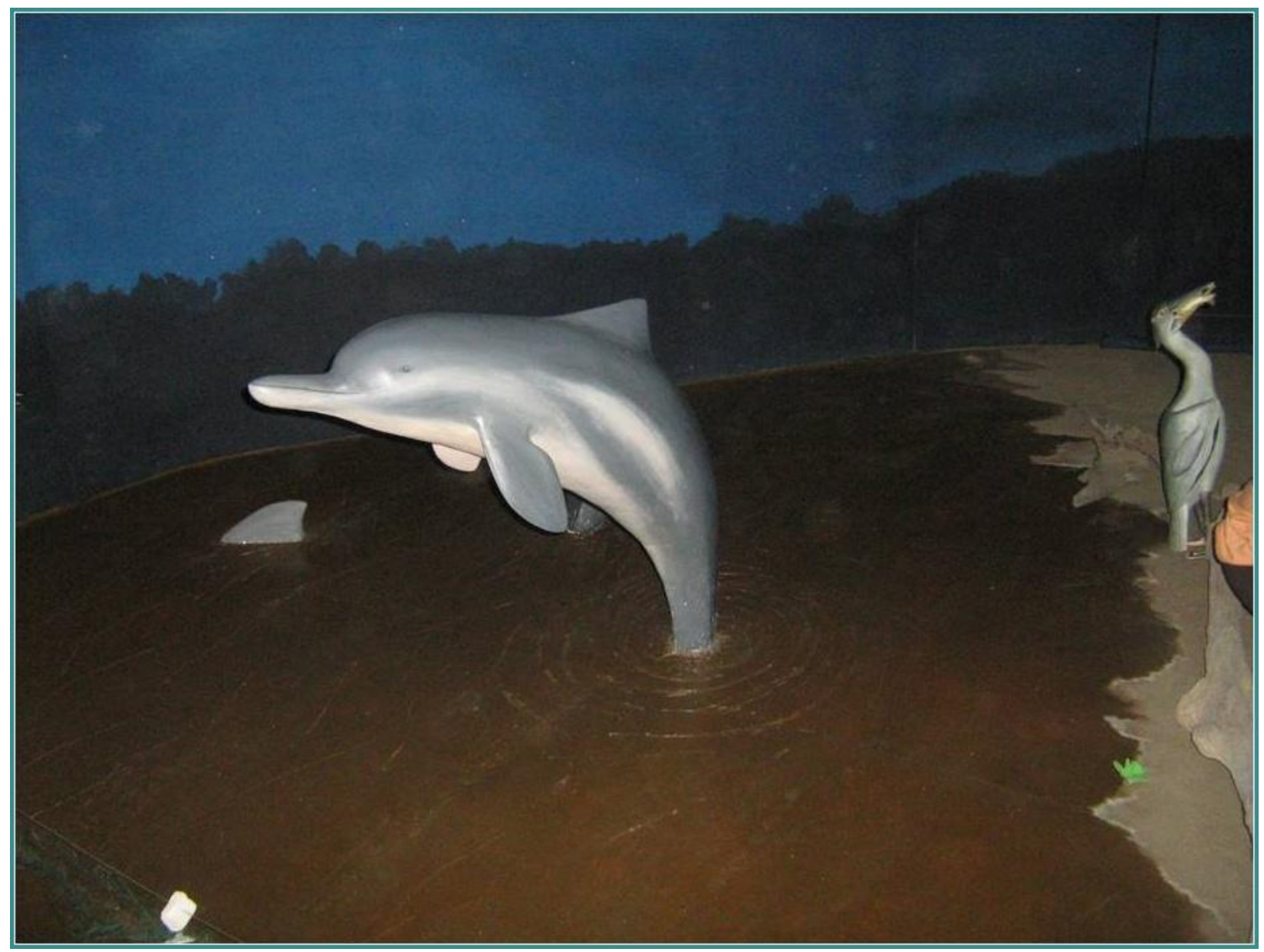

Este delfín disponible en el centro Natutama, elaborado por los niños y artesanos de la región, en ambientes artificiales que muestran la interacción en el ecosistema acuático, evidencia como a través del reconocimiento de la vida y sus bondades se pueden hacer cambiar actitudes y crear buenos hábitos de cuidado y conservación 
Titulo:

\section{GRAN DIVERSIDAD DE FLORA Y FAUNA}

Fecha: 4 de mayo de 2009

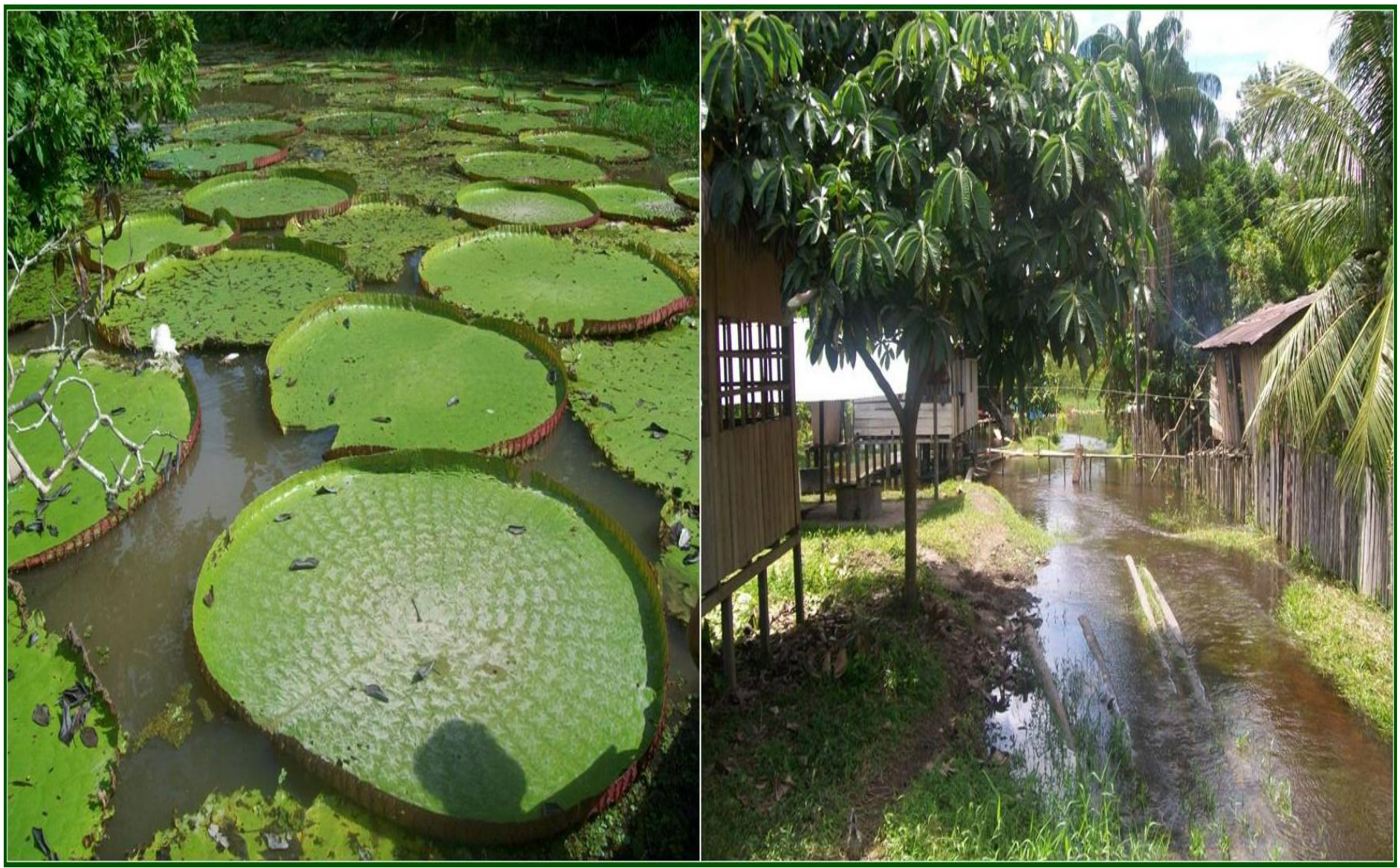

El río Amazonas nos dio la oportunidad de observar las victorias regias, que son un gran atractivo que demuestra la grandiosa diversidad existente en la zona; sus mágicas flores nos deslumbraron hasta el punto de sentirnos alagados por la naturaleza. 


\section{Titulo:}

\section{VISITA A LA UNIVERSIDAD NACIONAL EN LETICIA}

Fecha: 5 de mayo de 2009

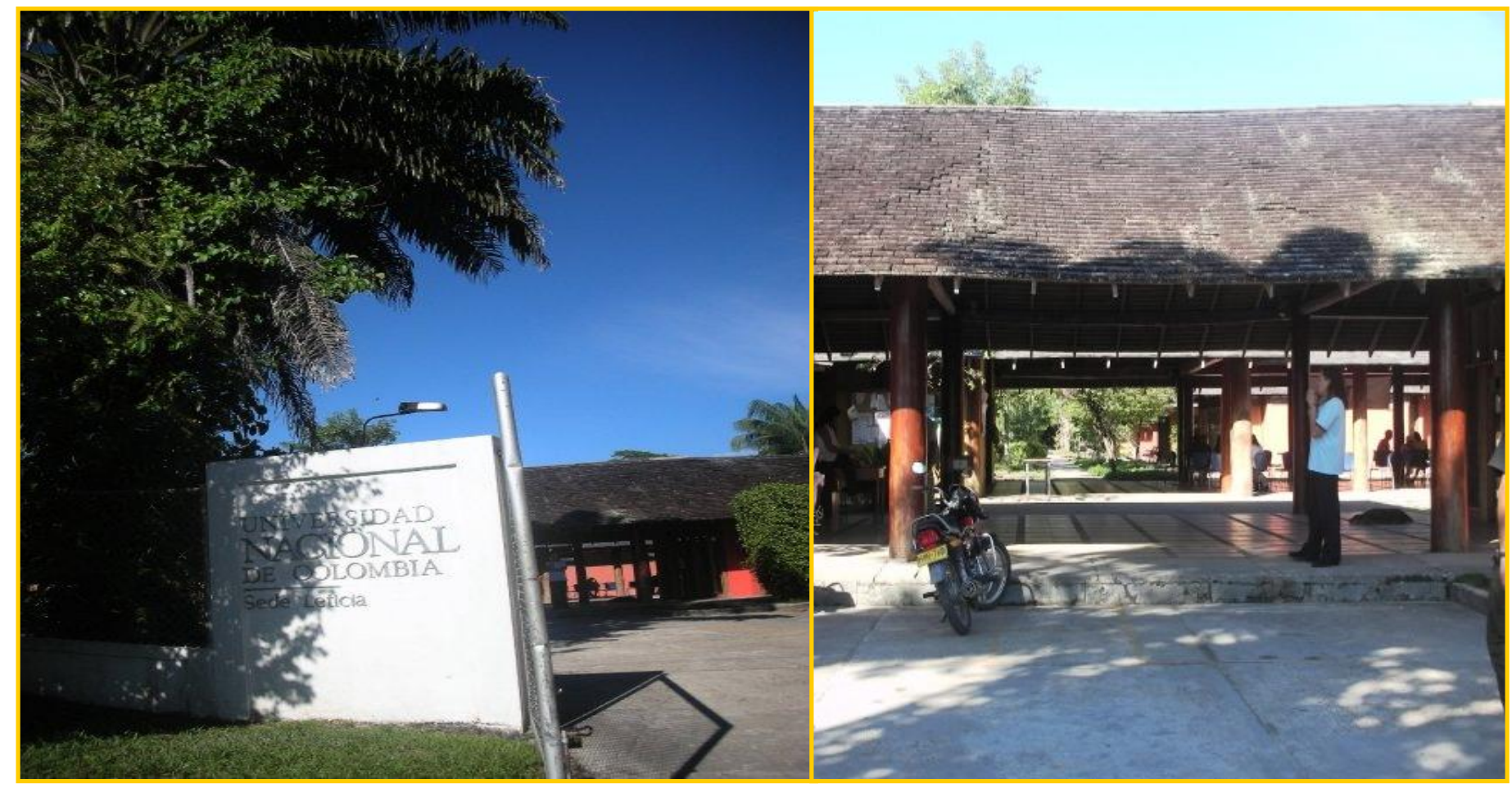

La Universidad Nacional se ha constituido en un espacio, donde se le brinda a la población del Amazonas la oportunidad de explorar su territorio desde otra perspectiva, generando un nuevo significado de este. Además, les brinda la oportunidad a estudiantes que no pertenecen a esa región conocerla y aplicar sus conocimientos en este lugar que se caracteriza por su diversidad tanto cultural como biológica. 
Titulo:

\section{FIN DE LA AVENTURA AMAZÓNICA}

Fecha: 6 de mayo de 2009

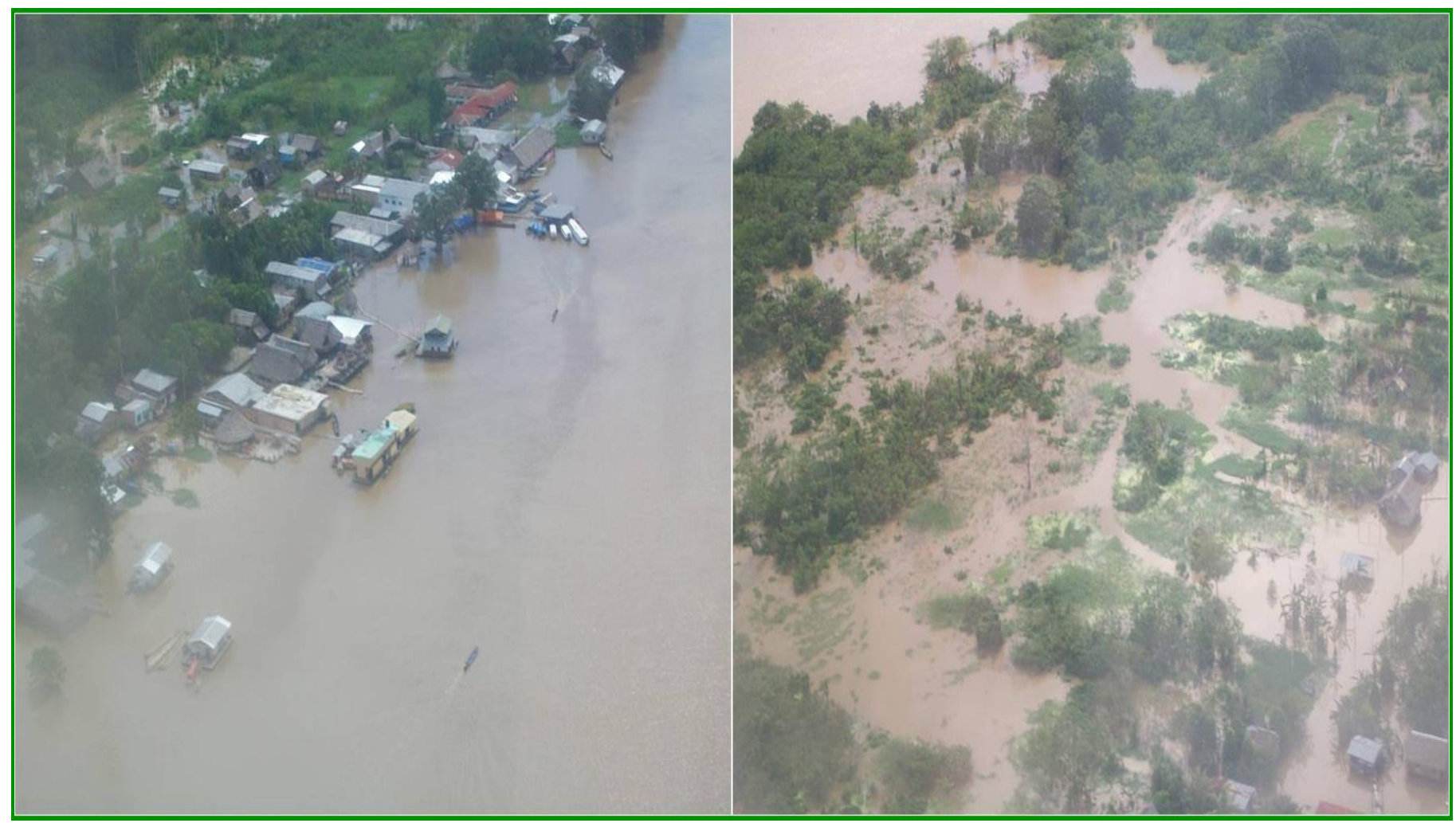

Desde el Puerto de Leticia se observa la grandeza e imponencia de nuestra hermosa selva. Lastimosamente toda nuestra felicidad se vio opacada por la partida hacia la ciudad pero nunca olvidaremos aquella mágica tierra que por 10 días nos entregó 10 mejor de ella con sus tradiciones, gente, cultura, y diversidad, dejando en nuestros corazones grandes deseos de volver 